\title{
A Community Welfare Model Interdependent with Productive, Civil Economy Clusters: A New Approach
}

\author{
Gaetano Giunta 1 ,2, Giovanni Giunta ${ }^{3}$, Liliana Leone4, Domenico Marino5, Gaspare Motta ${ }^{2,6}$, \\ Angelo Righetti ${ }^{2,7}$, Domenico Marino ${ }^{5}$ \\ ${ }^{1}$ Interuniversitary Horcynus Orca Foundation, Capo Peloro, Messina, Italy \\ ${ }^{2}$ Community Foundation of Messina, Forte Petrazza, Messina, Italy \\ ${ }^{3}$ Faculty of Physics, Ludwig-Maximilian-Universität, Munich, Germany \\ ${ }^{4}$ CEVAS Research and Evaluation Center, Rome, Italy \\ ${ }^{5}$ P.A.U. Department, Mediterranean University of Reggio Calabria, Reggio Calabria, Italy \\ ${ }^{6}$ Mental Health Department, ASP of Messina, Messina, Italy \\ ${ }^{7}$ KIP International School, FAO Building E, Rome, Italy \\ Email: dmarino@unirc.it
}

Received 18 May 2014; revised 20 June 2014; accepted 17 July 2014

Copyright (C) 2014 by authors and Scientific Research Publishing Inc.

This work is licensed under the Creative Commons Attribution International License (CC BY).

http://creativecommons.org/licenses/by/4.0/

(c) (i) Open Access

\section{Abstract}

In this paper we will present a new model of social policy related with productive, civil economy clusters able to generate an evolved community welfare, currently experimented in the area of the Strait of Messina. The approach is based on anthropological postulates much more complex than the concept of homo oeconomicus and it focuses on mesoscopic socio-economic-ecological systems. The theoretical description is supported by a mathematical model completely self-consistent and therefore is able to generate predictions easily verifiable through "experimental measurements". The logical scheme is based on the idea that local, human and economic development feeds on and amplifies social capital, people's instrumental freedoms and the economic resources of the analyzed clusters.

\section{Keywords}

Community Welfare, Civil Economy, Evolved Social District, Social Capital, Capabilities

\section{Introduction}

Since 1955 Kuznets' empirical studies [1] have denied Solow’s classical approaches to economy, according to

How to cite this paper: Giunta, G., Giunta, G., Leone, L., Marino, D., Motta, G., Righetti, A. and Marino, D. (2014) A Community Welfare Model Interdependent with Productive, Civil Economy Clusters: A New Approach. Modern Economy, 5, 914-923. http://dx.doi.org/10.4236/me.2014.58084 
which inequality is an incentive for growth. Indeed, comparing the empirical data, it has been discovered that the countries that have manifested greater growth during the last few years were those that had a higher level of equality.

Subsequent checks on the empirical data [2]-[4] have confirmed Kuznets' results, finally putting in doubt the results of the theoretical models of neoclassical style.

Historically established studies falsify the Solow approaches, which are based on assumptions of perfect rationality and on mechanisms of the accumulation of capital. According to these assumptions, people would choose to base on the criteria of maximization of profit or, in a more generalized form, of utility (this latter point will be discussed further ahead). A classical hypothesis, therefore, would suggest that with equal information every person and every economic agent would choose in the same way. The anthropological reductionism, the homo oeconomicus, that A. Sen called the "crazy rational", is completely without many fundamental components of human nature, as will be seen further ahead. Indeed, it is not surprising how results on a large, experimental, economic scale confirm the poverty of the anthropological assumptions of the classical approaches of economy [5]. Engel [6], in a review of the results of 328 different experiments for a total of more than 28,000 observations, calculates that only $36 \%$ of people behave like homo oeconomicus, revealing, for example, that they are completely devoid of pro-social attitudes during these experiments. Students of economic faculties had the highest percentage (about 40\%) whilst it decreases significantly (below 20\%) for adults and elderly people. On the other hand, nowadays it certainly is no longer true that accumulation of capital automatically activates a real economy, therefore generating economic development.

Finally, it is known that people who are in conditions of extreme deprivation manifest socio-economic choices characterized by a highly economic irrationality.

From what has been said it is clear why, in local contexts that have fallen under the poverty threshold trap, economic paradigms inclusive with respect to weak subjects, for example with respect to people with mental health problems, who are the object of our study, should be radically re-established from more complex anthropological models than reductionist assumptions of perfect rationality.

\section{Anthropological Assumptions for a New Model of Welfare Policy}

Here below shows (Figure 1), in a schematic way, the logical sequence of the mechanisms of people's choices and therefore of the economic agents of our social model from which we can draw important preliminary conclusions to re-establish welfare policies and those of structurally integrated local development.

People choose and act on the basis of the construction of a mediation object. The sphere of their choice certainly has a rational component and is linked to the health, gender and age of each individual. It is certainly affected by a psycho-social dimension (needs, beliefs - that is, what appears realistic can be implemented) and by a psychological dimension that is built around that dynamic and very personal non-equilibrium which oscillates between the desires and fears of every person. However, the weight that each individual attributes to their fears and desires, expectations and needs, heavily depends on their condition. Personal components of a psychological type cannot fail to be held in serious consideration in micro-based socio-economic paradigms [7]-[11].

The weight that each person gives to their needs and fears with respect to their actual expectations to emerge from, for example, conditions of poverty, addiction or deprivation, or in any case with respect to the real possibility of converging concrete expectations towards their own desires, depends on the urban and human landscape in which they live. It depends, therefore, on the physical and relational micro-climate in which they live. Their choices are based on a contextual balance, not an individual one; more correctly, on Aoki collective dynamics [12]. If people perceive mainly hawk contexts (to quote the language of the theory of games) their choices will be trapped by their fears and needs; if, on the other hand, contexts of doves are perceived, namely cohesion, mechanisms of sharing, cooperation and the project of desires are more easily triggered. Therefore, contexts heavily condition individuals' choices and thus local economies.

In addition to this horizontal level of the construction of social cohesion, there is a (temporal) vertical level that can provide qualitative elements so that man, in his complexity and not in the false caricature (homo oeconomicus) of classical economic paradigms, is at the centre of the processes of the physical and socio-economic transformation of the territory: endogenous approaches cannot help but establish their roots in the social capabilities of local communities, but at the same time they can't avoid evolving within innovative dynamics which hide the territories' capacity to hold and attract creative talents and to put a value on scientific and technological 


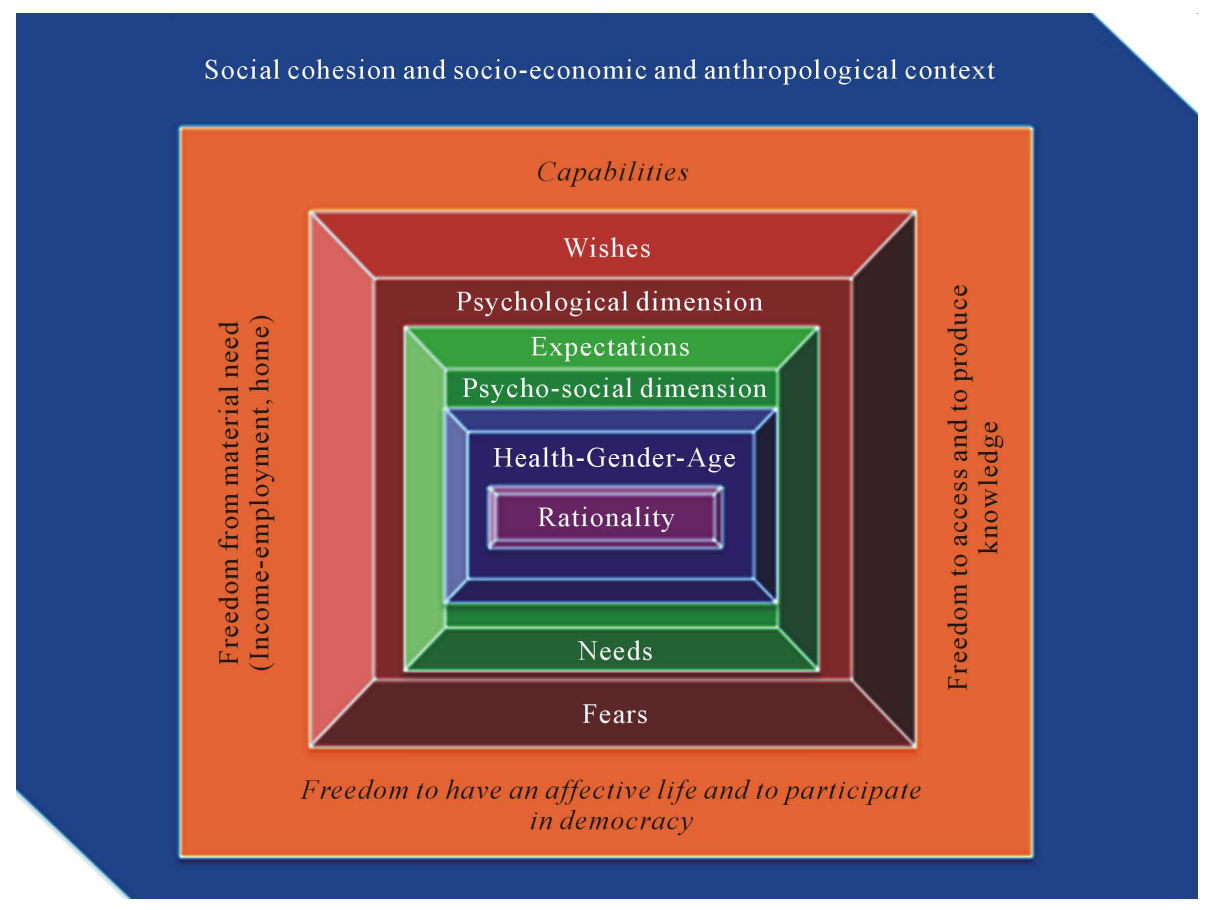

Figure 1. The choice model of the people that is the basis of the present approach.

innovations, albeit with sustainable limits. The realization that human activity has become a critical force in determining the fate of an increasingly wide range of biophysical systems constrains any attempt to explain and plan for the future, starting from human activities that are culturally, technically and economically connoted. This is equivalent to putting a constraint of correlation and social responsibility on future generations.

It is evident that at this point of reflection we are still, albeit in a generalized form, in the context of economic utilitarianism with environmental constraints. If we should micro-establish new socio-economic paradigms only starting from the search for utility, or also for personal happiness, we must be aware that these models may be compatible (in terms of paretian economic equilibrium) with situations of strong economic and social inequality, indeed even with situations of substantial exploitation. This equilibrium (of the poverty trap) becomes possible because more fragile people, deprived of their liberty, tend to remain trapped by their need to survive and, consequently, they don't have the courage to ask for (to actually imagine) changes and/or take action for them. Their expectations are crushed, without any ambition for the few things considered possible. Disillusionment drives away the desire from anything that seems possible and slows down positive behaviours aimed at getting out of conditions of poverty, addiction and deprivation. The policies to combat poverty, addictions and deprivation must necessarily be complex and must involve structural actions addressed to the system and aimed at the promotion of social cohesion and socio-economic contexts with respect to the development of personalized projects for the expansion of personal freedom (as we will see further ahead). They must create the right conditions in order for people to have a real chance of deciding which type of life they would like to live [13] [14].

The informative basis of economic models founded on absolute rationality or also on utilitarianism is insufficient. The convergence of actual expectations towards the sphere of collective and personal desires is linked to the level of people's capabilities, and this fact constitutes the human horizon needed to guide the development of people, societies and even economies.

If one of our aims is, therefore, to understand the real possibilities that every person has to pursue and achieve their goals, we must take account not only of that person's main assets but also of the relational and personal characteristics that govern the processes of converting assets into the capability of promoting their own purposes. For example, an elderly person or someone who is disabled or in poor health could be at a disadvantage, even with more substantial assets than a young person who is in good health.

There are many elements that influence the relationship between income, well-being and freedom. The personalization of policies seems to us to be an absolutely necessary strategical option. In this respect, let us remember 
that Amartya Sen defines function as what a person can want, that is what a person values (from being fed to being looked after, from the need to participate to that of socializing, etc) and capabilities as the collection of alternative combinations of functions that each person is able to achieve. The capabilities are therefore a sort of substantial freedom, freedom to put in action various alternative styles of life [15].

The expansion of real freedoms is therefore the end, but also the means of human development.

If we bring what has been said to the micro-foundational language used so far, there is no doubt that the capabilities of some functional areas can push the sphere of choice and of actual expectations towards their wishes and towards dynamics of change, even in hostile environments, also with respect to highly unbalanced socio-economic equilibriums. A. Sen demonstrated mathematically that paretian efficiency cannot be respected at the same time as freedom, and freedom shall be anchored to a functional socio-economic paradigm for human development and even, as said before, to economic development.

Our aim is to model socio-economic paradigms that can bring freedom to weaker people and environmental sustainability as external constraints to the logic of the maximization of profit.

In accordance with the most advanced research in economy and on disability [16] [17] and with the most advanced testing of local welfare it can be shown that the areas of operations more closely related to economic development are [18] [19]:

- Overcoming deprivations caused by the lack of and/or inadequacy of income/employment and the precariousness of living;

- Knowledge;

- Participation and democracy.

Recent studies [20] show a positive correlation between social capital, capabilities and economic development of the ESD.

The study is following the story of the ESD born in the area of the Strait of Messina, according to the approach developed in this paper.

In the particular case of Messina, the validity of the model has been experimentally verified. The variables are easily measured within the ESD: the social capital through statistical analysis and a study based on network analysis, the ability of people through the ICF method of classification introduced by the World Health Organization and economic resources from the quantitative analysis of the budgets of the ESD constituent organizations.

A reflection about these empirical results suggests the following mathematical model.

\section{The Model}

At a conceptually strategic level, inclusive local development plans in areas falling under the poverty trap and characterized by great inequality in the distribution of wealth and by a low propensity to social cohesion should implement, in an interdependent way, custom projects for inclusion in the areas of main human functions mentioned above and at the same time promote socio-economic systems with high capital, responsible on a social and environmental level and able to generate a climate of trust, which from here on in we will call Evolved Social Districts (ESD). The use of the term "District" is connected to the Italian tradition of production systems, as well as evolving into the idea of Evolved Cultural Districts [21].

The ESD was established to promote the creation of prolific interconnections between production systems, welfare systems, endowment of knowledge, research and development, and social capabilities in the territories in which it operates.

The starting point is formed by analytical reports, which govern the composition and the evolution of the ESD. They relate to the presence of historically determined multiple balances present at local level and which are substantiated in a differential linked to several different institutional functions, local cultures, popular innovative capabilities, production systems and allocations of capital stock.

From an economic point of view, ESD operates in a bottom-up type of logic, which guarantees greater diversity and increasing cooperation among the actors in the field [22].

Moreover, the economies of network (which also include the volumes determined by the economic demand that arises from the wider community of stakeholders of the ESD) form an important base that guarantees a break-even for the single enterprises that are part of the clusters.

From a community and socio-sanitary point of view there is no doubt that the ESD is the background that in- 
fluences and modifies the most important proximal and distal environmental determinant of health and of well-being. The health determinants are classified by WHO according to a multilevel model, including lifestyles, social networks, community relationships, socio-economic and socio-cultural context, access to education and employment. Since the ESD model, contrary to the atomistic approaches (a more or less institutionalizing service, the single cooperative insertion, etc), generates alternatives with respect to the main human functional areas described in the previous chapter, thereby creating a micro-climate generator of social freedoms.

Last, but not least, the promotion of systems of high social capital with a mesoscopic dimension, where stable forms of economic cooperation are tested, eases the territorial transition from non-cooperating companies towards cooperating companies [23] [24].

Therefore, the ESD can represent an open nucleus that is able to bring about larger changes and to build up a favorable environment increasing exchange of resources (human, cognitive, economical, etc) with relevant players that are external with respect to the local system. The latter is a necessary condition for activating people, communities and therefore the economies of the areas in which it works.

The conditions that produce effective and durable self-governance of common pool resources and the processes of knowledge sharing, decision-making, trust-based relationships and norms has been widely investigated by the Nobel Prize in Economics ElinorOstrom. Her Theory of Commons [25] was developed to explain the success or failure of collective solutions produced by the communities and institutions to solve the problem of the management of limited common-pool resources at risk of depletion such as water, forests, fishing, urban spaces and finally also [26]. Institutions are here understood as cultural products that facilitate and support collective action, in which subjects are coordinated and act jointly. Studies demonstrated, theoretically and empirically, that many successful institutions are rich mixtures of "private-like" and "public-like" not necessarily based on legal regulation quite the contrary on community-based solutions [27] [28]. There is a strict correspondence between the mechanisms, the system of rules and the ESD of Messina's governance structures, with the eight "design principles" identified by the theory for a stable local common-pool resources management.

Individuals are conceived as "students fallible", people are considered for the resources they bring and not just for failures-interests and preferences, are not designed in order to maximize their utility but rather as moral individuals with "a complex sense of justice, not reducible to those modelled by utilitarianism” [29].

This explains how new paradigms for local development cannot be separated from the implementation of models of community welfare that are structurally interconnected with forms of productive civil economy [30] [31]-[35], environmentally sustainable and organized in a cluster and in networks of clusters, which can create many opportunities, act as environmental facilitators for weaker people, recognizing their different stories, relational potential, individual skills, the extent of their desires and fears, of their expectations and needs which dynamically characterize every person.

Effective paradigms for local development are, therefore, functionally schematized as a sort of policies, mechanisms, algorithms which feed on and amplify social capital (of the reference socio-economic systems), people's capabilities(within observed systems) and the endogenous and exogenous economic resources that activate and then sustain the economic processes of the clusters.

The model and all the socio-economic variables are referred to an ESD.

This approach is alternative with respect to the classical institutionalized welfare, which only consume social capital (isolating people), personal capabilities (making their illnesses more chronic) and economic resources not connecting to forms of productive economies (Figure 2).

The scheme graphically summarizes what has just been said:

The modelling, therefore, concerns the development of mesoscopic territorial units of cooperative clusters, otherwise called ESD.

That is:

$x(t)=$ The numerical value of the social capital of the ESD referred to at time $t$ (estimated through a synthetic indicator normalized to 1 )

$y(t)=$ The numerical value of the average level of capabilities of people working within the ESD at time $t$ (estimated through a synthetic indicator normalized to 1 )

$z(t)=$ The numerical value of the economic resources of the ESD at time $t$ (normalized to its maximum value)

The theoretical approach summarized above suggests writing the following system of nonlinear differential equations to describe the tested welfare model: 


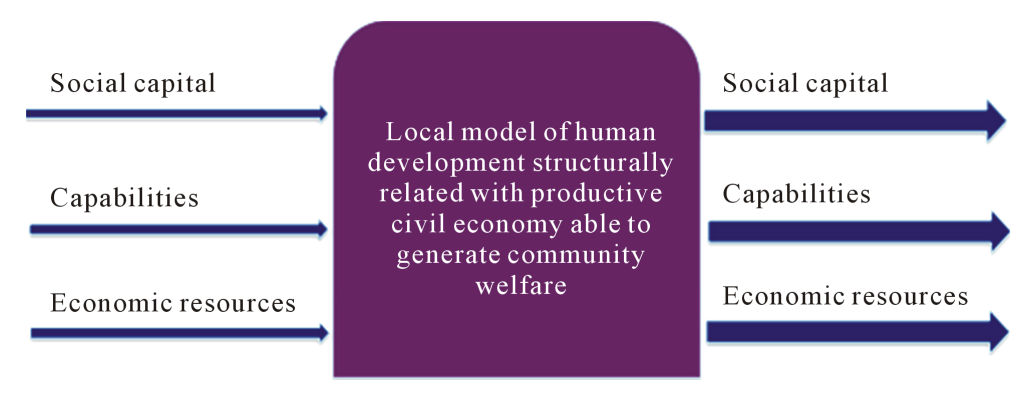

Figure 2. Logical scheme of the theoretical approach referred to an ESD.

$$
\left\{\begin{array}{l}
\dot{x}(t)=x(t) y(t) z(t)[1-x(t)]-B x(t) \\
\dot{y}(t)=x(t) y(t) z(t)[1-y(t)]-B y(t) \\
\dot{z}(t)=x(t) y(t) z(t)[1-z(t)]-B z(t)
\end{array}\right.
$$

In the previous system:

- $\dot{x}(t), \dot{y}(t)$ and $\dot{z}(t)$ represent the time derivatives of $x(t), y(t)$ and $z(t)$;

- The product $x(t) y(t) z(t)$ describes the complexity of the system and the positive correlations of the three dynamic variables;

- The terms $[1-x(t)],[1-y(t)],[1-z(t)]$ constitute a sort of ecological constraint of the system. They introduce the constraint in the mathematical model of the finiteness of resources at stake $x(t), y(t)$ and $z(t)$, which as we have said, are by definition normalized to 1 ;

- The terms $B x(t), B y(t), B z(t)$ quantify in a linear manner, the coupling between the ESD and the referred territorial context which constitutes a sort of external field that tends to renormalize the evolutionary experience of the District. The coupling parameter $B$ naturally depends on the territorial space in which the ESD operates and of which the dynamics are certainly much slower. For this reason it is correctly, in first approximation, considered as constant.

\section{Results}

The system of differential Equations (1) that models the welfare paradigm, the object of our study, was solved numerically on varying parameter $B$. This allowed to analyse in a comprehensive way the solution space and to immediately check the qualitative coherence of the model to the empirical analyses.

The study of the fixed points, together with the numerical analysis of the eigenvalues and eigenvectors of the system (1), allowed to trace the bifurcation diagram, identifying the attractors of $x(t), y(t)$ and $z(t)$ according to parameter $B$.

Figure 3 is of great interest and reveals predictions that are not trivial. It shows that there are two behaviour classes of the mathematical model according to the coupling value with the external field $B$. For $B<0.14814$ there are two lines of attractors of the system. The first describes the minimum attractor which coincides with the $\mathrm{x}$-axis; the second describes the maximum attractor and describes the system capacity on varying $B$.

Therefore, depending on the initial conditions of the combination that is of $x_{0}, y_{0}$ and $z_{0}$, the system can evolve towards its minimum attractor $(0)$ or towards its maximum attractor (system capacity).

Figure 4 and Figure 5 show the two dynamic features. The first was obtained in case $B=0.1$ and $x_{0}=y_{0}=z_{0}$ $=0$, and the second was calculated by assuming $B=0.1$ and $x_{0}=y_{0}=z_{0}=0.5$.

Figure 6 shows the boundary surfaces between the two possible dynamics for the variables of the system in case $B=1$.

If the initial conditions are above the surface designed for points in Figure 6 the system will evolve to its capacity. If the initial conditions are below the surface traced plotted in the figure, the system will gradually and fatally dissipate its resources towards the cancellation of them.

\section{Conclusions}

This result gives the first clear indications for the policies: 


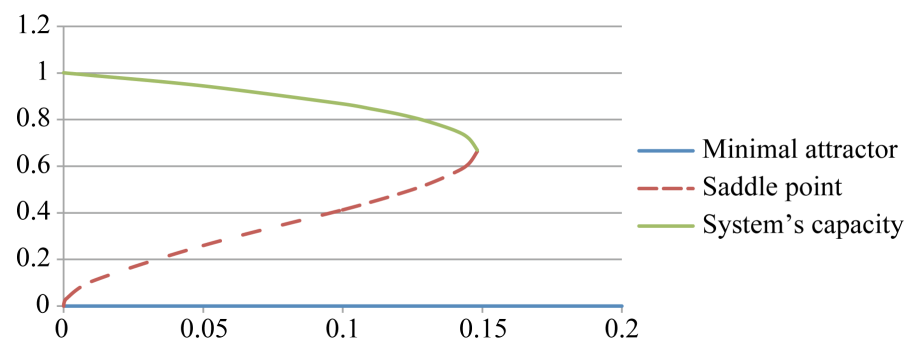

Figure 3. The bifurcation diagram.

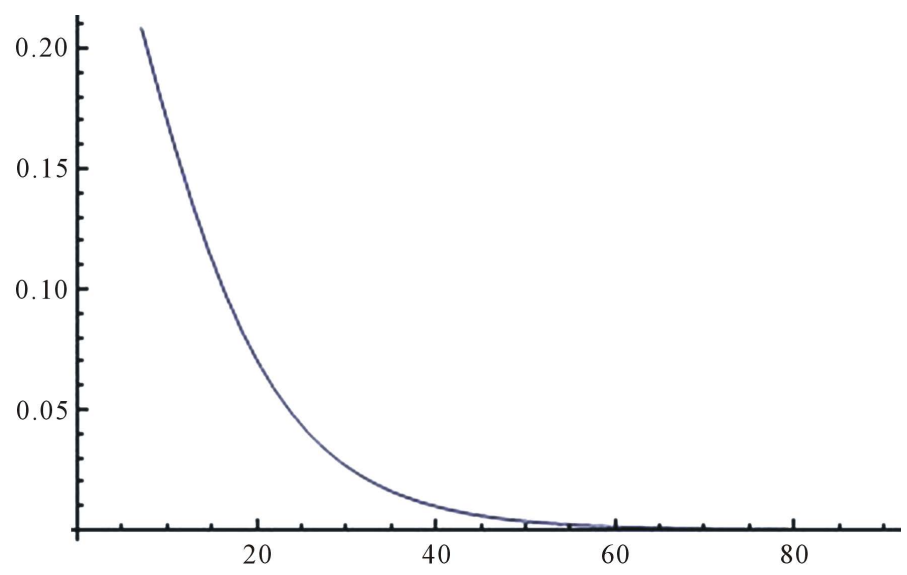

Figure 4. Trajectory type towards the minimum attractor.

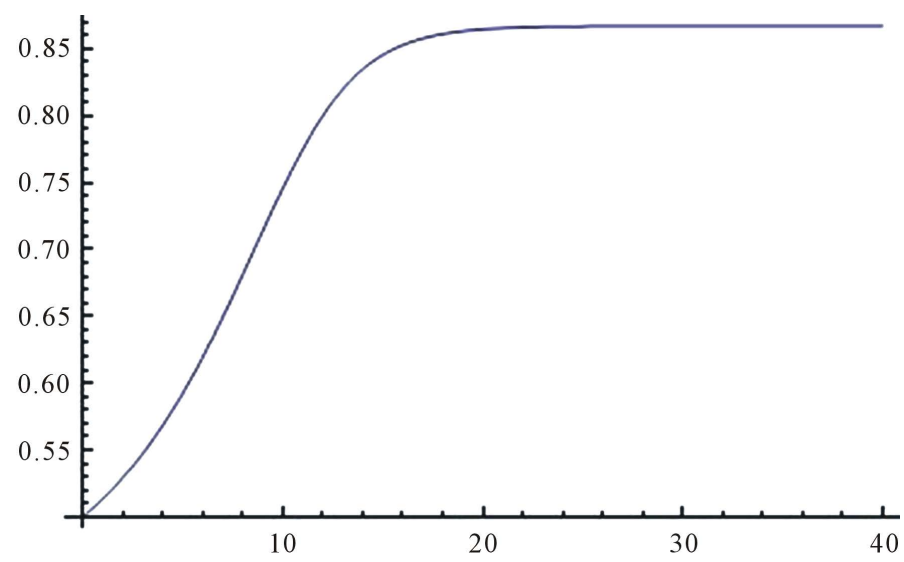

Figure 5. Trajectory type towards the capacity attractor.

1) The allocation of resources is more effective if it is oriented to high social capital socio-economic systems and with high capability levels;

2) Welfare and/or atomic policies do not effectively contribute to lasting change, neither personal nor community and generally are only wasteful without resources;

3) There are thresholds below which economic investment is ineffective. The more you refer to high social capital and high level of capabilities socio-economic systems the more these thresholds are lowered.

For $B>0.14814$ the space for solutions changes its nature, the capacity attractor of the system disappears and the ESD resources inevitably evolve towards the minimum attractor. The value $B=0.14814$ is thus a critical point, a kind of threshold above which the ESD inevitably falls into an evolutionary state of poverty trap, similar to the larger territories conditions in which it operates. 


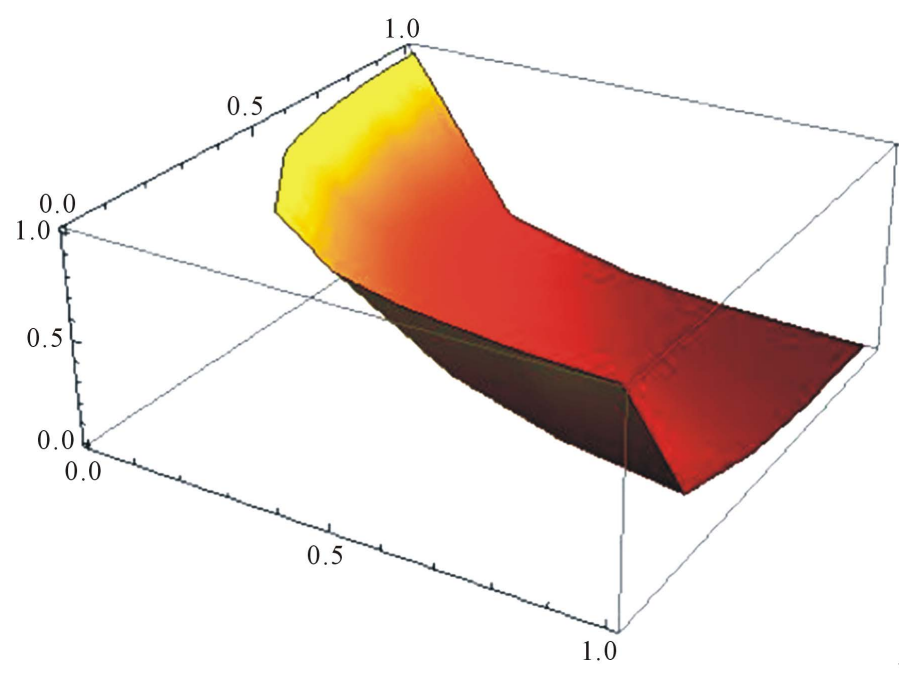

Figure 6. Boundary surfaces of the initial conditions of the social capital, capabilities and economic resources of the ESD between the dynamics of cancellation of the same system resources and evolution dynamics towards maximum capacity.

In local systems that therefore start from extreme conditions of poverty and inequality must operate systemically to enhance local socio-economic platforms and connect them directly to non-local and international networks, outside the local system. It is possible only through these actions to promote opening policies.

Recent theories of econophysics [18] seem to confirm what has just been stated. In fact, they indicate that, in an invariant manner compared to the geographical scale with which phenomena are observed, there is a strong correlation between poor social cohesion, processes of impoverishment of the territories and structuring on them of non-democratic attractors of wealth and therefore deeply disproportionate income, knowledge and opportunity. Of course, the deep-rooted presence of organized crime and/or the presence of state organizations distorting equal opportunities (the latter conditions being structural in many areas of the Mediterranean regions), with their forms of control over the territory and with their distorting ability of the market, amplify fragmentation and social control and therefore cause the amplification of a polarized geometry of wealth and opportunities.

The studies just mentioned, based on the Isingreticular systems, have drawn predictive considerations on the complex systems that simulate open socio-economic areas.

The predictive model based on microscopic interactions between economic agents predicts several stages on a microscopic scale:

- greatly impoverished system;

- greatly unfairly system;

- birth of socio-economic platforms and cooperative behaviours;

- fair system.

The study of the conditions (the model parameters) that determine the phase transitions, re-interpreted, provides important economic policy suggestions concerning the problem of inequality in the distribution of wealth:

- The opening level of the economic system makes the ability to attract resources increase. However a sort of poverty trap exists, that is a poverty level below which the further opening of the economy system becomes counterproductive, if not counterbalanced by strong local political cohesion;

- An equal wealth distributed with wide clusters of cooperation produces not only social benefits, but also economic ones. In fact the system, if open, in these conditions, is a resources attractor;

- In systems that start off from conditions of poverty and great inequality and territories in which, as in the south of the Mediterranean, have merged liberal practices with ancient proprietorial practices, it is necessary to work systemically to develop local socio-economical platforms and link them to international networks, even outside the local system and through these behaviours promote opening policies.

Ultimately this model, consistent with the present study, indicates that the transition between the first two steps toward the second two seems possible through the implementation of local policies strongly oriented to 
reward the cohesion and cooperative behaviour and internationalization policies and partnerships, interdependent with the first, which aim to produce flows of economic resources and knowledge that will directly improve the socio-economic clusters, generators of long networks, that are self-organized on the territories.

The theoretical model developed in this work is completely self-consistent and therefore able to generate indications which are purely predictive. In addition, its validity can be experimentally verified, since the variables are easily measurable within the ESD: the social capital, for example, through a study based on network analysis, the ability of people through the ICF method of classification introduced by the World Health Organization and economic resources from the quantitative analysis of the budgets of the ESD constituent organizations.

A research project designed to empirically test the theoretical model is already in progress. The study is following the story of the ESD born in the area of the Strait of Messina, according to the approach developed in this paper.

\section{References}

[1] Kuznets, S. (1955) Economic Growth and Income Inequality. The American Economic Review, 45, 1-28.

[2] Alesina, R. and Rodrik, D. (1994) Distributive Politics and Economics Growth. Quarterly Journal of Economics, 109, 465-490. http://dx.doi.org/10.2307/2118470

[3] Perotti, R. (1996) Growth, Income Distribution and Democracy: What the Data Say. Journal of Economic Growth, 1, 149-187. http://dx.doi.org/10.1007/BF00138861

[4] Person, T. and Tabellini, G. (1994) Is Inequality Harmful for Growth? The American Economic Review, 84, 600-621.

[5] Becchetti, L. (2011) Beyond the Homo Economicus. Working Papers 97 AICCON.

[6] Engel, C. (2011) Dictator Games: A Meta Study. Experimental Economics, 14, 583-610. http://dx.doi.org/10.1007/s10683-011-9283-7

[7] Kahneman, D. (1994) New Challenges to the Rationality Assumption. Journal of Institutional and Theoretical Economics (JITE), 150, 18-36.

[8] Tversky, A. and Kahneman, D. (1974) Judgment under Uncertainty: Heuristics and Biases. Science, New Series, 185, 1124-1131.

[9] Kahneman, D. (2003) A Psychological Perspective on Economics. The American Economic Review, 93, 162-168. http://dx.doi.org/10.1257/000282803321946985

[10] Kahneman, D. (2003) Experiences of Collaborative Research. American Psychologist, 58, 723-730. http://dx.doi.org/10.1037/0003-066X.58.9.723

[11] Kahneman, D., Krueger, A.B., Schkade, D., Schwarz, N. and Stone, A. (2004) Toward National Well-Being Accounts. The American Economic Review, 94, 429-434. http://dx.doi.org/10.1257/0002828041301713

[12] AokiM. (2002) Modeling Aggregate Behavior and Fluctations in Economics. Cambridge University Press, Cambridge.

[13] Sen, A. (1992) Inequality Reexamined. Harvard University Press.

[14] Nussbaum, M. (1999) Sex and Social Justice. Oxford University Press, New York

[15] Sen, A. (1999) Development as Freedom. Oxford University Press, New York.

[16] Nussbaum, M. (2007) Frontiers of Justice. Disability, Nationality, Species Membership. Scandinavian Journal of Disability Research, 9, 133-136. http://dx.doi.org/10.1080/15017410601003171

[17] Borgnolo, G., De Camillis, R., et al. (2009) ICF e Convenzione ONU sui diritti delle persone con disabilità. Erickson.

[18] Giunta, G. and Marino, D. (2011) An Explicative Model of Wealth Distribution. International Journal of Applied Economics and Econometrics, 19, 66-75.

[19] Giunta, G., et al. (2011) Le conseguenze della crisi viste da Sud—Dossier sulle povertà e sulle policy per un autentico sviluppo umano. EGA Edition.

[20] Giunta, G., et al. (2014) Sviluppo è coesione e libertà : Il caso del Distretto Sociale Evoluto di Messina—HDECivil Economy.

[21] Sacco, P.L. and TavaniBlessi, G. (2005) Distretti culturali evoluti e valorizzazione del territorio. Global \& Local Economic Review, 8, Edizioni Tracce.

[22] Bianchi, P. (1995) Le Politiche industriali dell’Unione Europea. Il Mulino.

[23] Nowak, M.A. (2006) Five Rules for the Evolution of Cooperation. Science, 314, 1560-1563. http://dx.doi.org/10.1126/science.1133755 
[24] Nowak, M.A. and Highfield, R. (2012) Super Cooperators: Altruism, Evolution, and Why We Need Each Other to Succeed. Free Press, New York.

[25] Ostrom, E. (1990) Governing the Commons: The Evolution of Institutions for Collective Action. Cambridge University Press, Cambridge. http://dx.doi.org/10.1017/CBO9780511807763

[26] Hess, C. and Ostrom, E. (2007) Understanding Knowledge as a Commons: From Theory to Practice. The MIT Press, Cambridge, Massachusetts.

[27] Marino, D., et al. (2009) The Attitudes, Motivations and Satisfaction of Volunteers. International Journal of Applied Economics and Econometrics, 3.

[28] Schenkel, M., Ermano, P. and Marino, D. (2014) Recent Trends in the Supply and Demand of Volunteers. American Journal of Industrial Business and Management, 4, 319-331.

[29] Vitale, T. (2010) L'arte e la scienza dell'associazione. Il nobel per l'economiaalla politologa ElinorOstrom. Aggiornamenti Sociali, 61.

[30] Bruni, L. (2009) L’impresa civile. Università Bocconi Editore.

[31] Bruni, L. and Zamagni, S. (2004) Economia civile. Il Mulino.

[32] Bruni, L. and Zamagni, S. (2009) Dizionario di economia civile. Città Nuova.

[33] Pelligra, V. (2007) I paradossi della fiducia. Il Mulino.

[34] Sacco, P.L. and Zamagni, S. (2002) Complessità relazionale e comportamento economico. Il Mulino.

[35] Sacco, P.L. and Zamagni, S. (2006) Teoria economica e relazioni interpersonali. Il Mulino. 
Scientific Research Publishing (SCIRP) is one of the largest Open Access journal publishers. It is currently publishing more than 200 open access, online, peer-reviewed journals covering a wide range of academic disciplines. SCIRP serves the worldwide academic communities and contributes to the progress and application of science with its publication.

Other selected journals from SCIRP are listed as below. Submit your manuscript to us via either submit@scirp.org or Online Submission Portal.
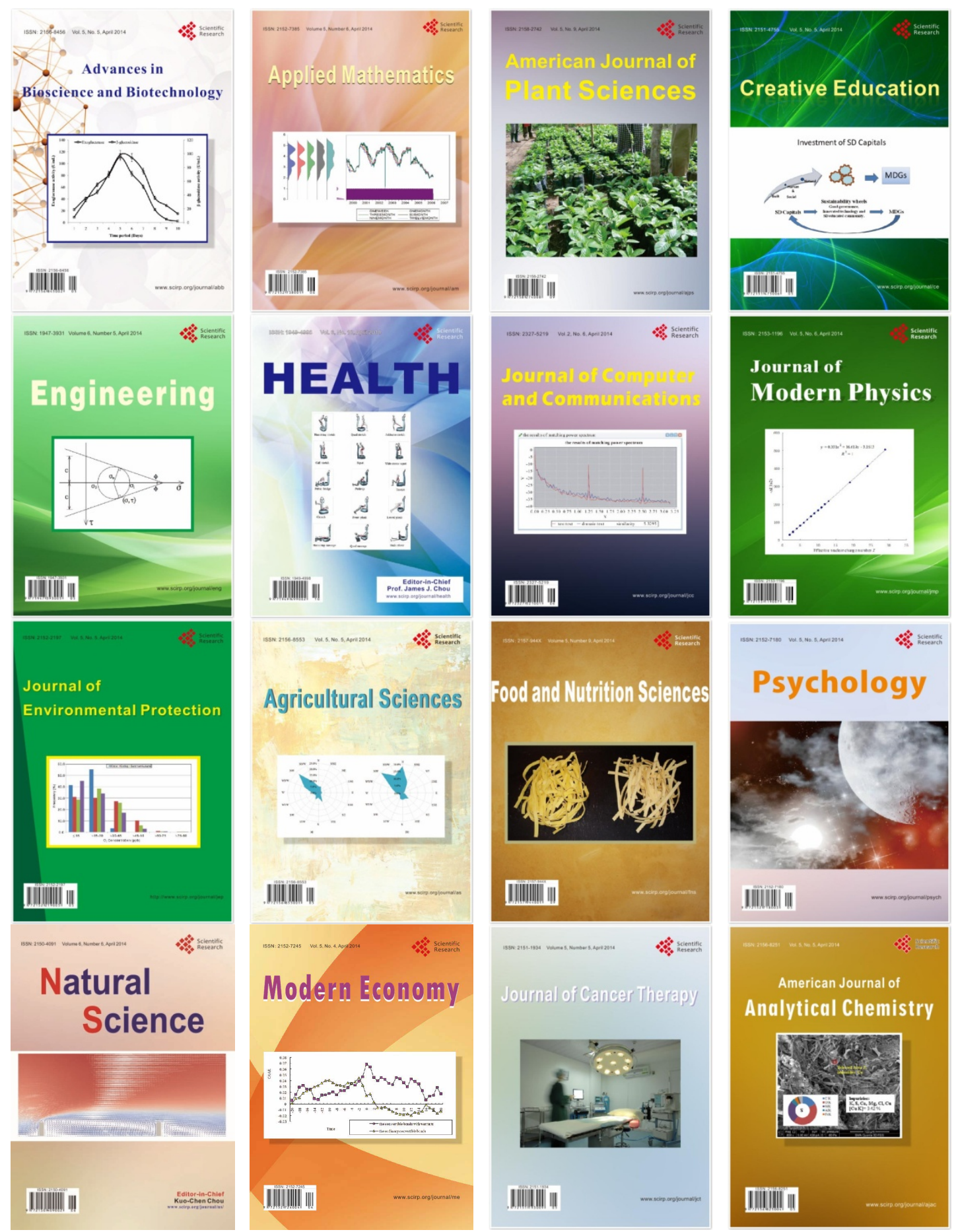